\title{
Human Non-hypertrophic Nonunion Tissue Contains Osteoblast Lineage Cells and E-BMP-2 Activates Osteogenic and Chondrogenic Differentiation
}

\section{Ryo Yoshikawa}

Department of Orthopaedic Surgery, Kobe University Graduate School of Medicine, Kobe, Japan Tomoaki Fukui

Department of Orthopaedic Surgery, Kobe University Graduate School of Medicine, Kobe, Japan Keisuke Oe

Department of Orthopaedic Surgery, Kobe University Graduate School of Medicine, Kobe, Japan Yohei Kumabe

Department of Orthopaedic Surgery, Kobe University Graduate School of Medicine, Kobe, Japan Takahiro Oda

Department of Orthopaedic Surgery, Kobe University Graduate School of Medicine, Kobe, Japan

\section{Kenichi Sawauchi}

Department of Orthopaedic Surgery, Kobe University Graduate School of Medicine, Kobe, Japan Kyohei Takase

Department of Orthopaedic Surgery, Kobe University Graduate School of Medicine, Kobe, Japan

\section{Yuya Yamamoto}

Department of Orthopaedic Surgery, Kobe University Graduate School of Medicine, Kobe, Japan

\section{Yoshitada Sakai}

Division of Rehabilitation Medicine, Kobe University Graduate School of Medicine, Kobe, Japan

\section{Ryosuke Kuroda}

Department of Orthopaedic Surgery, Kobe University Graduate School of Medicine, Kobe, Japan

Takahiro Niikura ( $\nabla$ tniikura@med.kobe-u.ac.jp)

Department of Orthopaedic Surgery, Kobe University Graduate School of Medicine, Kobe, Japan

\section{Research Article}

Keywords: non-hypertrophic nonunion, bone morphogenetic protein-2, fracture healing

Posted Date: February 25th, 2022

DOI: https://doi.org/10.21203/rs.3.rs-1381413/v1 
License: (c) (i) This work is licensed under a Creative Commons Attribution 4.0 International License. Read Full License 


\section{Abstract}

Background: Nonunions without hypertrophic callus formation has been identified based on X-ray findings, and we have defined it as non-hypertrophic nonunion. Bone morphogenetic protein-2 (BMP-2) is a well-known growth factor for bone regeneration, and Escherichia coli-derived BMP-2 (E-BMP-2) is considered a low-cost alternative to currently available products for humans. In this in vitro study, we examined the proliferation capability and osteogenic and chondrogenic differentiation potential of nonhypertrophic nonunion cells (NHNCs), and the effect of E-BMP-2 on them.

Methods: We enrolled five patients with non-hypertrophic nonunion. NHNCs isolated from nonunion tissue sampled during surgery were cultured, passaged, and counted every 14 days. The surface antigen profiles of NHNCs were characterized using flow cytometry. Osteogenic differentiation capability was assessed using Alizarin Red S staining, alkaline phosphatase activity assay, and real-time reverse transcription-polymerase chain reaction (RT-PCR) after culturing in osteogenic medium. Furthermore, chondrogenic differentiation capability was assessed using Safranin-O staining and real-time RT-PCR after culturing in chondrogenic medium. To examine the effect of E-BMP-2 on the proliferation, osteogenic differentiation, and chondrogenic differentiation of NHNCs, they were cultured in each medium supplemented with $100 \mathrm{ng} / \mathrm{mL}$ E-BMP-2.

Results: NHNCs were homogenous fibroblastic adherent cells and long-lived through at least 10 passages, with a slight decline. Flow cytometry revealed that the cells were consistently positive for mesenchymal stem cell-related markers CD73 and CD105, and negative for the hematopoietic markers CD14 and CD45. NHNCs were capable of differentiating into osteoblast lineage cells; however, they did not have strong calcification or sufficient chondrogenic differentiation capability. E-BMP-2 did not affect the proliferative capability of the cells but improved their osteogenic differentiation capability by increasing alkaline phosphatase activity and upregulating the gene expression of osterix, bone sialoprotein, and osteocalcin. Moreover, E-BMP-2 enhanced their chondrogenic differentiation capability by upregulating the gene expression of aggrecan and collagen type II.

Conclusions: We showed for the first time that NHNCs had the capacity to differentiate into osteoblastlineage cells, although the chondrogenic differentiation potential was poor. Local application of E-BMP-2 with preservation of nonunion tissue could be a treatment option for non-hypertrophic nonunion by promoting osteogenesis and chondrogenesis.

\section{Background}

The bone healing process after a fracture is a complex interplay of mechanical and biological factors and $5-10 \%$ of fractures fail to heal, resulting in delayed union or nonunion. [1] Nonunion is difficult to treat and has a high financial impact; [2] the Weber and Cech classification [3] is most widely used to classify various types. However, it is not easy to distinguish nonunion based on the classification. Recently, considering the ease of judgment in clinical settings, we defined nonunion without radiological callus 
formation including oligotrophic, comminuted (torsion-wedge, dystrophic, and necrotic), defect, and atrophic types in the Weber and Cech classification as non-hypertrophic nonunion. [3, 4] Furthermore, we reported that the standardized uptake value on bone single-photon emission computed tomography is lower in non-hypertrophic than in hypertrophic nonunion. [5]

Assessment of biological activity in nonunion tissue is essential to develop effective treatment strategies for nonunion. We previously reported that tissue in hypertrophic nonunion contains multilineage mesenchymal progenitor cells, [6] and osteogenic cells are expressed in pseudoarthrosis tissue. [7] However, no study has investigated the cells derived from non-hypertrophic nonunion tissue and methods for improving the differentiation capability.

Recombinant human bone morphogenetic protein-2 (rhBMP-2) is a well-known growth factor in bone regeneration because of its high potency and ability to induce the osteogenic differentiation of osteoblasts and osteoblast precursors. [8-10] However, the production of large amounts of rhBMP-2 is costly because most rhBMPs are mainly purified from mammalian sources, such as Chinese hamster ovary (CHO) cells. [11] To solve this problem, Escherichia coli-derived BMP-2 (E-BMP-2) has been produced, at a cost that is expected to be lower, using a molecular unfolding and refolding technique as an alternative to mammalian cells. [12, 13] Yano et al. [14] reported that E-BMP-2 has comparable biological activity to BMP-2 produced in $\mathrm{CHO}$ cells. We previously demonstrated that E-BMP-2-loaded $\beta$ tricalcium phosphate granules effectively promote bone regeneration in long bone defects in vivo. [15] However, to the best of our knowledge, the effect of E-BMP-2 on nonunion cells has not been demonstrated.

In this in vitro study, we focused on non-hypertrophic nonunion with the aim of examining the proliferation capability and osteogenic and chondrogenic differentiation potential of tissue-derived nonhypertrophic nonunion cells (NHNCs), and the effect of E-BMP-2 on them. The results of this study may be used to determine whether E-BMP-2 could be a potentially useful treatment option for non-hypertrophic nonunion in the future.

\section{Methods}

\section{Patient characteristics}

Nonunion of bone was defined as the failure of a fracture to heal within 6 months in a patient who had not shown progressive bone repair radiographically within 3-6 months after the fracture. $[16,17]$ Patients with infections, tumors, autoimmune diseases, or other systemic bone-related diseases and those who were administered hormones, steroids, vitamin D, or calcium were excluded from this study.

Non-hypertrophic nonunion was defined as nonunion without radiological callus formation including oligotrophic, comminuted (torsion-wedge, dystrophic, and necrotic), defect, and atrophic types in the Weber and Cech classification and was confirmed by three senior orthopedic trauma surgeons. $[3,5]$ Five patients with non-hypertrophic nonunion surgically treated in our institution were enrolled (Table 1). The 
patient characteristics were as follows: mean age, 36.6 (range 20-59) years; sex, three male and two female patients; fracture sites, one tibial diaphysis, one clavicle diaphyseal, and three femoral diaphysis fractures. The initial treatments for original fractures consisted of conservative therapy for one patient, whereas the others underwent surgical treatments: intramedullary locking nail for three patients and plate-and-screw fixation for one. The duration from the initial fracture to the surgery for nonunion was 612 (mean, 9.9) months. The ethics committee of our hospital approved this study, and informed consent was obtained from all patients before participation.

Table 1

Cell sample data from five patients

\begin{tabular}{|llllll|}
\hline Patients & Sex & Age & Fracture site & Initial treatment & $\begin{array}{l}\text { Duration from fracture } \\
\text { (months) }\end{array}$ \\
\hline 1 & Female & 20 & $\begin{array}{l}\text { Clavicle } \\
\text { diaphysis }\end{array}$ & Conservative & 6 \\
\hline 2 & Male & 23 & Tibia diaphysis & $\begin{array}{l}\text { Intramedullary locking } \\
\text { nail }\end{array}$ & 10 \\
\hline 4 & Female & 59 & $\begin{array}{l}\text { Femoral } \\
\text { diaphysis }\end{array}$ & $\begin{array}{l}\text { Intramedullary locking } \\
\text { nail }\end{array}$ & 9.5 \\
\hline 5 & Male & 24 & $\begin{array}{l}\text { Femoral } \\
\text { diaphysis }\end{array}$ & $\begin{array}{l}\text { Plate-and-screw } \\
\text { fixation }\end{array}$ & 12 \\
\hline
\end{tabular}

\section{Isolation and culture of NHNCs}

NHNCs were isolated from nonunion tissue as previously described. $[6,7,18]$ The central portion of a small amount of the nonunion tissue obtained during the surgeries was carefully dissected to avoid contaminating the bone, periosteum, and muscle, and then cultured. The nonunion tissue was resected, washed with phosphate-buffered saline (PBS, Wako, Osaka, Japan), minced into small pieces, and cultured in the original medium (Om), a-modified minimum essential medium (Sigma-Aldrich, St. Louis, MO, USA) containing 10\% heat-inactivated fetal bovine serum (Sigma-Aldrich), $2 \mathrm{mM}$ L-glutamine (Gibco BRL, Grand Island, NY, USA), and antibiotics in a 100-mm culture dish.

The culture plates were incubated at $37^{\circ} \mathrm{C}$ in a humidified atmosphere of $5 \% \mathrm{CO}_{2}$. After a 7-day incubation, the culture dish was washed with PBS to remove nonviable cells and debris, and the culture medium was changed twice weekly. Approximately 2 weeks later, the adherent cells were harvested with $0.05 \%$ trypsin- $0.02 \%$ ethylenediaminetetraacetic acid (Wako) and passaged into culture flasks at a 
density of approximately $4 \times 10^{3}$ cells $/ \mathrm{cm}^{2}$ for further expansion. Cells from passages 3 to 4 were used in the following differentiation assays for each sample.

\section{Preparation of E-BMP-2}

The E-BMP-2 used in this study was produced and provided by Osteopharma (Osaka, Japan), and was dissolved in PBS (Wako) to $100 \mathrm{ng} / \mathrm{mL}$ according to the manufacturer's recommendations. Details of procedures for E-BMP-2 production have been reported. [14, 19] E-BMP-2 with a dimeric molecular structure was produced in human BMP-2 gene-transfected $E$. coli with a monomeric structure and stored in inclusion bodies that were collected. [20] The molecular structure was unfolded in protein-denaturing agents and then refolded to form dimeric E-BMP-2 by removing the denaturing agents. Dimeric E-BMP-2 was subsequently purified using several chromatography steps.

\section{Growth kinetics}

Cells at passage 3 that had reached subconfluence were replated and, after 2 weeks, the cells at passage 4 were passaged again. To examine long-term growth kinetics, the cells were counted using a hemocytometer every 14 days from passage 4 until passage 10.

Population doubling (PD), a method of calculating proliferative capability, was performed for each subculture using the following equation: $\mathrm{PD}=\left[\log _{10}(\mathrm{NH})-\log _{10}(\mathrm{~N} 1)\right] / \log _{10}(2)$, where $\mathrm{N} 1$ is the inoculum number, $\mathrm{NH}$ is the cell harvest number, and log is the logarithm. [21] The calculated PD increase was added to the PD levels of the previous passages to yield the cumulative PD level. First, NHNCs were maintained in the Om (Om group) and, then, to examine the effect of E-BMP-2 on proliferation, NHNCs were cultured in Om supplemented with $100 \mathrm{ng} / \mathrm{mL}$ E-BMP-2 (Om + BMP group). Histological images in both groups were visualized on day 7 at passage 4 and passage 10 using a BZ-X700 microscope (Keyence, Osaka, Japan).

\section{Immunophenotyping of NHNCs using flow cytometry}

The surface antigen profiles of NHNCs at passage 3 or 4 were characterized using flow cytometry. In total, $4 \times 10^{5}$ cells were incubated with the following phycoerythrin (PE)-conjugated anti-human antibodies: CD14, CD45, CD73, and CD105 (BD Biosciences, San Jose, CA, USA) for 60 min at $4^{\circ} \mathrm{C}$ in the dark. Nonspecific mouse PE-conjugated immunoglobulin G (IgG, BD Biosciences) was used as an isotype control. After incubation, cells were analyzed using the BD LSRFortessa flow cytometer (X-20, BD Biosciences). The data were analyzed using FlowJo software 10.7.1 (Treestar, Ashland, OR, USA) using a MAC $\AA$ workstation. The positive cell rate was expressed as the percentage of fluorescence intensity greater than $1 \times 10^{3}$. 


\section{Differentiation studies}

\section{Osteogenic induction}

To induce osteogenic differentiation, NHNCs were cultured for 28 days in an osteogenic medium consisting of the Om plus $10 \mathrm{nM}$ dexamethasone (Sigma-Aldrich), $10 \mathrm{mM} \beta$-glycerophosphate (SigmaAldrich), and $50 \mathrm{mg} / \mathrm{mL}$ ascorbic acid (Wako). [6] Cells from passages 3 to 4 were used in the osteogenic differentiation assays. NHNCs were cultured in 6-well plates at a density of approximately $4 \times 10^{3}$ cells $/ \mathrm{cm}^{2}$. NHNCs were maintained in osteogenic differentiation medium (Os group). Additionally, to examine the effect of E-BMP-2 on the osteogenic differentiation of NHNCs, they were cultured in osteogenic differentiation medium supplemented with $100 \mathrm{ng} / \mathrm{mL}$ E-BMP-2 (Os + BMP group).

Osteogenic differentiation was evaluated using Alizarin Red S (Hartman Leddon, Philadelphia, PA, USA) staining, alkaline phosphatase (ALP) activity assay, and real-time reverse transcription-polymerase chain reaction (RT-PCR) on day 7, 14, 21, and 28. Alizarin Red S staining was also used to assess mineralization in differentiated cultures. Histological sections stained with Alizarin Red S were also visualized using a BZ-X700 microscope. To quantitatively compare the mineralization of NHNCs, cells stained with Alizarin Red S were destained with ethylpyridinium chloride (Wako), the extracted stain was transferred to a 96well plate $(200 \mu \mathrm{L}$ per well), and the absorbance at $562 \mathrm{~nm}$ was measured using a microplate reader, as previously described. $[6,22]$ The cell layer from each well was sonicated using a Microson XL2000 ultrasonic cell disruptor (Misonix, Farmingdale, NY, USA) and stored at $-80{ }^{\circ} \mathrm{C}$ until assayed for ALP activity by measuring the release of $\mathrm{p}$-nitrophenol from $\mathrm{p}$-nitrophenylphosphate, monitored using a SensoLyte pNPP ALP assay kit (AnaSpec Corp, San Jose, CA, USA). The protein concentration was standardized using a bicinchoninic acid protein assay kit (Pierce Biotechnology Inc., Rockford, IL, USA). The expression of the osteoblast-related genes runt-related transcription factor 2 (RUNX2), osterix (OSX), activating transcription factor 4 (ATF4), collagen type I (COL 1A1), bone sialoprotein (BSP), and osteocalcin $(O C M)$ was measured using real-time RT-PCR.

\section{Chondrogenic induction}

To induce chondrogenic differentiation, a three-dimensional pellet culture system was established for 21 days. Approximately $2.5 \times 10^{5}$ cells in a $15-\mathrm{mL}$ polypropylene tube were pelleted by centrifugation. [6, 23] The cells were treated with chondrogenic medium consisting of high-glucose Dulbecco's modified Eagle's medium (Invitrogen, Carlsbad, CA, USA) with $100 \mathrm{nM}$ dexamethasone, $50 \mathrm{mg} / \mathrm{mL}$ ascorbic acid, $0.4 \mathrm{mM}$ proline (Sigma-Aldrich), $1 \%$ insulin-transferrin-selenium plus Premix (Sigma-Aldrich), and $10 \mathrm{ng} / \mathrm{mL}$ recombinant human transforming growth factor- $\beta 3$ (R\&D Systems, Minneapolis, MN, USA). [6, 7, 18, 24] $\mathrm{NHNCs}$ were maintained in chondrogenic medium (Ch group). Additionally, to examine the effect of $\mathrm{E}$ BMP-2 on the chondrogenic differentiation of NHNCs, they were cultured in chondrogenic differentiation medium supplemented with $100 \mathrm{ng} / \mathrm{mL}$ E-BMP-2 (Ch + BMP group). 
Chondrogenic differentiation was evaluated using Safranin-O (Chroma, Munster, Germany) staining and real-time RT-PCR on day 21. Safranin-0 staining was also used to assess the general morphology and proteoglycan content in cartilaginous tissues. For histological assessment, the pellets were embedded in paraffin, sectioned, and visualized using a BZ-X700 microscope. The expression of chondrocyte-related genes aggrecan $(A C A N)$, collagen type II (COL2A1), collagen type X (COL 10A1), and Sry-type high-mobility group box 9 (SOX9) was measured using real-time RT-PCR.

\section{Isolation of control cells using reamer-irrigator-aspirator (RIA)}

For Alizarin Red S and Safranin-O staining, positive control cells were isolated using the RIA system, a relatively new process for harvesting autologous bone grafts by reaming the intramedullary canal of long bones. [25] This system has been reported to contain mesenchymal stromal cells (MSCs) with high osteogenic and chondrogenic potency. $[26,27]$ The cells were cultured under the same conditions as the NHNCs were without E-BMP-2.

\section{Real-time RT-PCR analysis}

Total RNA was isolated from each sample using the RNeasy mini kit (Qiagen, Valencia, CA, USA) according to the manufacturer's instructions. Total RNA was reverse transcribed into single-strand complementary DNA (cDNA) using a high-capacity cDNA RT kit (Applied Biosystems, Foster City, CA, USA). The converted cDNA samples were amplified using PCR with Taq Gold DNA polymerase (Applied Biosystems). Measurements were performed in duplicate using an Applied Biosystems 7500 real-time PCR system and the primer sequences were purchased from Thermo Fisher Scientific Inc. (Waltham, MA, USA) (Table 2). Real-time RT-PCR was performed using a thermal cycler (Programme Temperature Control System PC-707, ASTEC, Fukuoka, Japan). The housekeeping gene glyceraldehyde 3-phosphate dehydrogenase (GAPDH) was analyzed to monitor RNA loading. NHNCs in the Os group on day 7 and the Ch group were used as controls. 
Table 2

Gene-specific primer sequences for real-time reverse transcription-polymerase chain reaction (RT-PCR)

\begin{tabular}{|c|c|}
\hline Gene & Primer Sequences \\
\hline \multirow[t]{2}{*}{ GAPDH } & Forward: 5'-CGTCTTCACCACCATGGAGA-3' \\
\hline & Reverse: 5'-CGGCCATCACGCCACAGTTT-3' \\
\hline \multirow[t]{2}{*}{$R U N X 2$} & Forward: 5'-ATGCTTCATTCGCCTCACAAAC-3' \\
\hline & Reverse: 5'-CCAAAAGAAGTTTTGCTGACATGG-3' \\
\hline \multirow[t]{2}{*}{ os $x$} & Forward: 5'-CGGGACTCAACAACTCT-3' \\
\hline & Reverse: 5'-CCATAGGGGTGTGTCAT-3' \\
\hline \multirow[t]{2}{*}{ ATF4 } & Forward: 5'-CTGACCACGTTGGATGACAC-3' \\
\hline & Reverse: 5'-GGGCTCATACAGATGCCTCT-3' \\
\hline \multirow[t]{2}{*}{ COL $1 A 1$} & Forward: 5'-AGGAATTCGGCTTCGACGTT-3' \\
\hline & Reverse: 5'-GGTTCAGTTTGGGTTGCTTG-3' \\
\hline \multirow[t]{2}{*}{$B S P$} & Forward: 5'-AAACGAAGAAAGCGAAGCAGAA-3' \\
\hline & Reverse: 5'-GCTGCCGTTGCCGTTTT-3' \\
\hline \multirow[t]{2}{*}{ OCN } & Forward: 5'-CATGAGAGCCCTCACA-3' \\
\hline & Reverse: 5'-AGAGCGACACCCTAGAC-3' \\
\hline \multirow[t]{2}{*}{$A C A N$} & Forward: 5'-TGAGGAGGGCTGGAACAAGTACC-3' \\
\hline & Reverse: 5'-GGAGGTGGTAATTGCAGGGAACA-3' \\
\hline \multirow[t]{2}{*}{ COL2A1 } & Forward: 5'-TTTCCCAGGTCAAGATGGTC-3' \\
\hline & Reverse: 5'-CTTCAGCACCTGTCCACCA-3' \\
\hline \multirow[t]{2}{*}{ COL $10 A 1$} & Forward: 5'-GCCCAAGAGGTGCCCCTGGAATAC-3' \\
\hline & Reverse: 5'-CCTGAGAAAGAGGAGTGGACATAC-3' \\
\hline \multirow[t]{2}{*}{ SOX9 } & Forward: 5'-ATCTGAAGAAGGAGAGCGAG-3' \\
\hline & Reverse: 5'-TCAGAAGTCTCCAGAGCTTG-3' \\
\hline \multicolumn{2}{|c|}{$\begin{array}{l}\text { GAPDH, glyceraldehyde 3-phosphate dehydrogenase; } R U N X 2 \text {, runt-related transcription factor 2; OSX } \\
\text { osterix; } A T F 4 \text {, activating transcription factor } 4 ; C O L 1 A 1 \text {, collagen type I; } B S P \text {, bone sialoprotein; } O C N \text {, } \\
\text { osteocalcin; } A C A N \text {, aggrecan; } C O L 2 A 1 \text {, collagen type II; } C O L 1 O A 1 \text {, collagen type X; SOX9, Sry-type } \\
\text { high-mobility group box } 9 \text {. }\end{array}$} \\
\hline
\end{tabular}

\section{Statistical analysis}


All data were analyzed using the statistical package for the social sciences (SPSS) 22.0 (IBM Japan, Tokyo, Japan). The Kruskal-Wallis test and Dunn-Bonferroni post hoc test were used to compare weekly differences in the absorbance of Alizarin Red S staining and ALP activities in the Os and Os + BMP groups. To determine if there were significant differences in PD, absorbance of Alizarin Red S staining, ALP activity, and real-time RT-PCR among the groups (Om vs. Om + BMP, Os vs. Os + BMP, and Ch vs. Ch + BMP), we performed the Mann-Whitney U test. Differences were considered statistically significant at $p<$ 0.05 .

\section{Results}

\section{Growth kinetics and morphological characteristics}

The cells showed longevity in culture and sufficient capacity for expansion. The calculated PD suggested that the NHNCs could be cultured through at least 10 passages with a slight decline in proliferation rates (Fig. 1a). In addition, there was no difference in proliferation capability between the Om and Om + BMP groups at each subculture stage. All NHNCs at passages 4 and 10 in both groups had similar fibroblastlike spindle-shaped morphology and the cell density was reduced with each passage (Fig. 1b). E-BMP-2 had no influence on the appearance of NHNCs.

\section{Immunophenotypes}

Flow cytometric analysis showed that the NHNCs derived from all patients were negative for the hematopoietic stem cell markers CD14 and CD45, and positive for the mesenchymal stem cell markers CD73 and CD105 (Fig. 2). The positive expression rates (mean \pm standard deviation) of CD14, CD 45, CD73, and CD105 were $4.02 \pm 4.94 \%, 2.09 \pm 2.61 \%, 99.3 \pm 0.80 \%$, and $98.5 \pm 1.50 \%$, respectively.

\section{Osteogenic differentiation potential}

After a 28-day incubation under osteogenic conditions (Os group), the NHNCs formed a slightly mineralized matrix, observed as a nodule stained red by Alizarin Red S (Fig. 3a). In addition, mineralized bone nodule formation was more prominent in the Os + BMP group than in the Os group. Quantification of the Alizarin Red S staining intensity revealed that mineralization in the NHNCs increased with time in both groups. However, there were no significant weekly differences in the Os group $(p=0.068)$. In contrast, in the Os + BMP group, the mineralization on day 28 was significantly higher than that on day 7 $(p=0.001)$. In addition, the mineralization activity of the Os + BMP group on day 28 was significantly higher than that of the Os group on day 28 ( $p=0.016)$ (Fig. 3b).

ALP activity increased with time in both groups but there were no significant weekly differences in the Os group ( $p=0.070)$. In contrast, the ALP activity was significantly higher on day 28 than on day 7 in the Os + BMP group $(p=0.017)$. In addition, on day 28 , the ALP activity in the Os + BMP group was significantly higher than that in the Os group ( $p=0.016$, Fig. 4). 
The expression levels of RUNX2, OSX, ATF4, COL1A1, BSP, and OCN were measured using real-time RTPCR on day 7, 14, 21, and 28 (Fig. 5). In the Os group, the expression levels of RUNX2, ATF4, and COL1A1 increased with time and decreased on day 28; however, the levels of $O S X, B S P$, and $O C N$ were not remarkably upregulated with time. In the Os + BMP group, the expression levels of $O S X, B S P$, and $O C N$ were higher than those in the Os group. The difference was significant for OSX expression on day 14, 21, and $28(p=0.009, p=0.047$, and $p=0.016$, respectively), $B S P$ expression on day 14,21 , and $28(p=0.028$, $p=0.047$, and $p=0.028$, respectively), and $O C N$ expression on day 21 and $28(p=0.028$ and $p=0.009$, respectively). Although the expression levels of RUNX2, ATF4, and COL 1A1 in the Os + BMP group were higher than those in the Os group, the differences were not significant.

\section{Chondrogenic differentiation potential}

Glycosaminoglycan deposition in the Ch + BMP group was observed as red staining of the extracellular matrix by Safranin-0, although this was slight in the Ch group (Fig. 6a). The expression levels of $A C A N$ and $C O L 2 A 1$ in the $C h+B M P$ group were significantly higher than those in the Ch group (both $p=0.005$, Fig. 6b). However, the expression levels of $C O L 10 A 1$ and SOX9 did not differ between the groups.

\section{Discussion}

The results of this study demonstrated that NHNCs were capable of proliferating and differentiating into osteoblast-lineage cells, but did not exhibit sufficient chondrogenic differentiation potential. In addition, EBMP-2 enhanced both the osteogenic and chondrogenic differentiation of the cells. In this study, the NHNCs showed fibroblast-like spindle-shaped cells resembling bone marrow MSCs cells (BMSCs). The proliferation capability of NHNCs was maintained even at passage 10 , similar to that of hypertrophic nonunion and pseudoarthrosis tissue-derived cells as previously described. [6, 7]

Furthermore, the cell viability of the nonunion fracture site was reported to be similar to that of normal BMSCs derived from the human iliac crest. [28] Moreover, cells isolated from atrophic fracture nonunion have been reported to exhibit lower proliferation capability than BMSCs because of increasing cell senescence. [24] The NHNCs were actively proliferative at early passages, but this ability decreased slightly during the late passages. We considered that the proliferation capability of the NHNCs might have been reduced by an increased level of cell senescence because they were atrophic nonunion-derived cells.

Flow cytometric analysis revealed that the NHNCs exhibited a phenotype similar to that of BMSCs. The capability of NHNCs to differentiate into osteoblast-lineage cells was determined using Alizarin Red S staining, ALP activity analysis, and real-time RT-PCR. The results suggested that the NHNCs have similar characteristics to cells from both hypertrophic nonunion and pseudoarthrosis tissue, which were shown to resemble BMSCs in our previous studies. [6, 7] However, the result of the Alizarin Red S staining comparing the RIA-derived cells revealed that the NHNCs were less calcified than the BMSCs, which might explain why NHNCs do not show callus formation on X-ray findings. [5] Based on the results of the real- 
time RT-PCR, we consider that this might also occur because the expression levels of $O S X, B S P$, and OCN are not upregulated.

BMP-2 has been widely studied as an osteogenic growth factor and demonstrated to induce bone formation. [29-31] However, the effect of BMP-2 treatment on nonunion remains unclear. [32] Zhang et al. [30] reported that BMP-2 causes a dose-dependent decrease in the proliferation of human tendon stem cells derived from the patellar tendons. Our results suggest that the concentration of E-BMP-2 we used on the NHNCs was appropriate because it showed no negative effect on the proliferative ability at each passage. The differentiation of BMSCs into osteoblasts is mainly mediated by master transcription factors such as RUNX2 and OSX, and BMP-2 stimulates their expression. In our study, E-BMP-2 promoted the osteogenesis of NHNCs by upregulating OSX expression; however, it did not upregulate RUNX2 expression in the NHNCs. We propose that RUNX2 upregulation in NHNCs by E-BMP-2 might occur before day 7, because BMP-2 upregulates RUNX2 expression to increase the number of osteoblasts during the early stages of osteoblastic differentiation. [33,34]

In our study, the chondrogenic differentiation potential of NHNCs was poor, which could be one of the factors involved in the development of non-hypertrophic nonunion. BMP-2 induces chondrogenic differentiation in various types of stem cells in vitro. [35] The results of this study suggested that treating NHNCs with E-BMP-2 induced their differentiation into chondrogenic cells by upregulating ACAN and collagen type II secretion. In contrast, E-BMP-2 treatment did not upregulate the expression of COL 10A1 or SOX9, which is a transcription factor known to be a master regulator of chondrogenesis. [36] We propose that $S O X 9$ upregulation in NHNCs by E-BMP-2 might occur before day 21. Furthermore, the change in COL 10A1 expression by E-BMP-2 was not detected likely because, as a specific marker for hypertrophic chondrocytes, COL $10 A 1$ is upregulated in the late stages of chondrocyte differentiation. In addition, this observation could further explain why a concentration of $100 \mathrm{ng} / \mathrm{mL}$ E-BMP-2 might be insufficient for inducing hypertrophic chondrocytes from NHNCs.

The treatment of hypertrophic nonunion, which is different from that of nonunion, usually requires stabilization of the nonunion site without local treatment such as curettage or bone grafting. This is because the tissue could maintain a reservoir of multilineage mesenchymal progenitor cells, which can transform into cartilage and bone-forming cells. [6] In contrast, the general approach for dealing with most non-hypertrophic nonunion involves improving biological activity by decortication or bone grafting and increasing nonunion site stability. [37, 38] Bone autograft is the safest and most effective grafting procedure for nonunion because it uses MSCs from the patient and growth factors to enhance osteogenesis and osteoinduction, respectively. [39] However, the autografts are frequently obtained from the iliac crest, which sometimes causes serious complications such as pain, fractures, bleeding, infection, and nerve palsy at the donor site. [40] In the future, these complications might be avoided by the local application of E-BMP-2 without resection of the nonunion tissue.

This study had some limitations that are worth mentioning. First, our study included only five patients with different backgrounds; therefore, further studies with larger sample sizes are required. Second, we 
did not directly compare the differentiation and other capabilities of NHNCs to other cells, such as those derived from hypertrophic nonunions. To determine the actual decrease in the capability of the NHNCs, it would be necessary to culture and compare them simultaneously. Finally, our study only investigated EBMP-2 at a concentration of $100 \mathrm{ng} / \mathrm{mL}$, and the effects of varying concentrations need to be examined to determine the appropriate dose.

\section{Conclusions}

We have shown for the first time that NHNCs were able to differentiate into osteoblast-lineage cells, but did not have a strong calcification or sufficient chondrogenic differentiation capabilities. Furthermore, EBMP-2 ameliorated the lack of osteogenic and chondrogenic differentiation potential of NHNCs without affecting their proliferation capability. Local application of E-BMP-2 with the preservation of nonunion tissue could be a future potentially useful treatment option for non-hypertrophic nonunion, through the promotion of osteogenesis and chondrogenesis.

\section{Abbreviations}

BMP-2: Bone morphogenetic protein-2; E-BMP-2: Escherichia coli-derived bone morphogenetic protein-2; NHNC: Non-hypertrophic nonunion cell; RT-PCR: Reverse transcription-polymerase chain reaction; rhBMP2: Recombinant human bone morphogenetic protein-2; CHO: Chinese hamster ovary; PBS: Phosphatebuffered saline; Om: Original medium; PD: Population doubling; Os: Osteogenic medium; ALP: Alkaline phosphatase; RUNX2: Runt-related transcription factor 2; OSX: Osterix; ATF4: Activating transcription factor 4; COL1A1: Collagen type l; BSP: Bone sialoprotein; OCN: Osteocalcin; Ch: Chondrogenic medium; ACAN: Aggrecan; COL2A1: Collagen type II; COL10A1: Collagen type X; SOX9: Sry-type high-mobility group box 9; RIA: Reamer-irrigator-aspirator; MSC: Mesenchymal stromal cell; GAPDH: Glyceraldehyde 3phosphate dehydrogenase; BMSC: Bone marrow mesenchymal stromal cell.

\section{Declarations}

\section{Ethics approval and consent to participate}

This study involving human participants was conducted in accordance with the ethical standards of the institutional and national research committee and with the 1964 Helsinki Declaration and its later amendments. The ethics committee of Kobe University approved this study (No. 1198), and informed consent was obtained from all patients before participation.

\section{Consent for publication}

Informed consent for publication was obtained from all participants included in the study.

\section{Availability of data and materials}


The datasets used and/or analysed during the current study are available from the corresponding author on reasonable request.

\section{Competing interests}

The authors declare that they have no competing interests.

\section{Funding}

No funding was received for this study.

\section{Authors' contributions}

TN, TF, KO, and YS conceived and designed the study; acquired, analyzed, and interpreted the data; and drafted and critically revised the manuscript. RK conceived and designed the study and drafted and critically revised the manuscript. RY acquired, analyzed, and interpreted the data and drafted and critically revised the manuscript. YK, TO, KS, KT, and YY acquired, analyzed, and interpreted the data. All authors read and approved the final manuscript.

\section{Acknowledgments}

The authors would like to thank Ms. K. Tanaka, Ms. M. Nagata, and Ms. M. Yasuda for their technical assistance. We also thank Dr. E. Nitta and Dr. R. Nitta for their expertise in flow cytometric analysis techniques. We would like to thank Editage (www.editage.jp) for English language editing.

\section{References}

1. Bishop GB, Einhorn TA. Current and future clinical applications of bone morphogenetic proteins in orthopaedic trauma surgery. Int Orthop. 2007;31:721-7. https://doi.org/10.1007/s00264-007-0424-8

2. Hak DJ, Fitzpatrick D, Bishop JA, Marsh JL, Tilp S, Schnettler R, et al. Delayed union and nonunions: epidemiology, clinical issues, and financial aspects. Injury. 2014;45;Suppl 2:S3-7. https://doi.org/10.1016/j.injury.2014.04.002

3. Weber BGCO. Pseudarthrosis. New York: Grune \& Stratton; 1976

4. Niikura T, Lee SY, Sakai Y, Nishida K, Kuroda R, Kurosaka M. Comparison of radiographic appearance and bone scintigraphy in fracture nonunions. Orthopedics. 2014;37:e44-50. https://doi.org/10.3928/01477447-20131219-16

5. Oe K, Zeng F, Fukui T, Nogami M, Murakami T, Matsumoto T, et al. Quantitative bone single-photon emission computed tomography imaging for uninfected nonunion: comparison of hypertrophic nonunion and non-hypertrophic nonunion. J Orthop Surg Res. 2021;16:125. https://doi.org/10.1186/s13018-021-02279-8

6. Iwakura T, Miwa M, Sakai Y, Niikura T, Lee SY, Oe K, et al. Human hypertrophic nonunion tissue contains mesenchymal progenitor cells with multilineage capacity in vitro. J Orthop Res. 
2009;27:208-15. https://doi.org/10.1002/jor.20739

7. Takahara S, Niikura T, Lee SY, Iwakura T, Okumachi E, Kuroda R, et al. Human pseudoarthrosis tissue contains cells with osteogenic potential. Injury. 2016;47:1184-90.

https://doi.org/10.1016/j.injury.2016.02.022

8. Keskin DS, Tezcaner A, Korkusuz P, Korkusuz F, Hasirci V. Collagen-chondroitin sulfate-based PLLASAIB-coated rhBMP-2 delivery system for bone repair. Biomaterials. 2005;26:4023-34. https://doi.org/10.1016/j.biomaterials.2004.09.063

9. Zara JN, Siu RK, Zhang X, Shen J, Ngo R, Lee M, et al. High doses of bone morphogenetic protein 2 induce structurally abnormal bone and inflammation in vivo. Tissue Eng Part A. 2011;17:1389-99. https://doi.org/10.1089/ten.TEA.2010.0555

10. Fung SL, Wu X, Maceren JP, Mao Y, Kohn J. In vitro evaluation of recombinant bone morphogenetic Protein-2 bioactivity for regenerative medicine. Tissue Eng Part C Methods. 2019;25:553-9. https://doi.org/10.1089/ten.TEC.2019.0156

11. Israel DI, Nove J, Kerns KM, Moutsatsos IK, Kaufman RJ. Expression and characterization of bone morphogenetic protein-2 in Chinese hamster ovary cells. Growth Factors. 1992;7:139-50. https://doi.org/10.3109/08977199209046403

12. JH. L, SJ. J, Ty K. Expression, purification and osteogenic bioactivity of recombinant human BMP-2 derived by Escherichia coli. J Tissue Eng Regen Med. 2011;8:8-15

13. Long S, Truong L, Bennett K, Phillips A, Wong-Staal F, Ma H. Expression, purification, and renaturation of bone morphogenetic protein-2 from Escherichia coli. Protein Expr Purif. 2006;46:374-8. https://doi.org/10.1016/j.pep.2005.09.025

14. Yano K, Hoshino M, Ohta Y, Manaka T, Naka Y, Imai Y, et al. Osteoinductive capacity and heat stability of recombinant human bone morphogenetic protein-2 produced by Escherichia coli and dimerized by biochemical processing. J Bone Miner Metab. 2009;27:355-63. https://doi.org/10.1007/s00774009-0040-3

15. Kuroiwa Y, Niikura T, Lee SY, Oe K, Iwakura T, Fukui T, et al. Escherichia coli-derived BMP-2-absorbed beta-TCP granules induce bone regeneration in rabbit critical-sized femoral segmental defects. Int Orthop. 2019;43:1247-53. https://doi.org/10.1007/s00264-018-4079-4

16. Megas P. Classification of non-union. Injury. 2005;36;Suppl 4:S30-7. https://doi.org/10.1016/j.injury.2005.10.008

17. Hernigou P, Poignard A, Beaujean F, Rouard H. Percutaneous autologous bone-marrow grafting for nonunions. Influence of the number and concentration of progenitor cells. J Bone Joint Surg Am. 2005;87:1430-7. https://doi.org/10.2106/JBJS.D.02215

18. Oe K, Miwa M, Sakai Y, Lee SY, Kuroda R, Kurosaka M. An in vitro study demonstrating that haematomas found at the site of human fractures contain progenitor cells with multilineage capacity. J Bone Joint Surg Br. 2007;89:133-8. https://doi.org/10.1302/0301-620X.89B1.18286

19. Ruppert R, Hoffmann E, Sebald W. Human bone morphogenetic protein 2 contains a heparin-binding site which modifies its biological activity. Eur J Biochem. 1996;237:295-302. 
https://doi.org/10.1111/j.1432-1033.1996.0295n.x

20. Matsumoto T, Toyoda H, Dohzono S, Yasuda H, Wakitani S, Nakamura H, et al. Efficacy of interspinous process lumbar fusion with recombinant human bone morphogenetic protein-2 delivered with a synthetic polymer and beta-tricalcium phosphate in a rabbit model. Eur Spine J. 2012;21:1338-45. https://doi.org/10.1007/s00586-011-2130-x

21. Cristofalo VJ, Allen RG, Pignolo RJ, Martin BG, Beck JC. Relationship between donor age and the replicative lifespan of human cells in culture: a reevaluation. Proc Natl Acad Sci U S A. 1998;95:10614-9. https://doi.org/10.1073/pnas.95.18.10614

22. Maeda T, Matsunuma A, Kurahashi I, Yanagawa T, Yoshida H, Horiuchi N. Induction of osteoblast differentiation indices by statins in MC3T3-E1 cells. J Cell Biochem. 2004;92:458-71. https://doi.org/10.1002/jcb.20074

23. Lee SY, Miwa M, Sakai Y, Kuroda R, Matsumoto T, Iwakura T, et al. In vitro multipotentiality and characterization of human unfractured traumatic hemarthrosis-derived progenitor cells: A potential cell source for tissue repair. J Cell Physiol. 2007;210:561-6. https://doi.org/10.1002/jcp.20890

24. Bajada S, Marshall MJ, Wright KT, Richardson JB, Johnson WE. Decreased osteogenesis, increased cell senescence and elevated Dickkopf-1 secretion in human fracture non union stromal cells. Bone. 2009;45:726-35. https://doi.org/10.1016/j.bone.2009.06.015

25. Schmidmaier G, Herrmann S, Green J, Weber T, Scharfenberger A, Haas NP, et al. Quantitative assessment of growth factors in reaming aspirate, iliac crest, and platelet preparation. Bone. 2006;39:1156-63. https://doi.org/10.1016/j.bone.2006.05.023

26. Kuehlfluck P, Moghaddam A, Helbig L, Child C, Wildemann B, Schmidmaier G, et al. RIA fractions contain mesenchymal stroma cells with high osteogenic potency. Injury. 2015;46;Suppl 8:S23-32. https://doi.org/10.1016/S0020-1383(15)30051-6

27. Toosi S, Naderi-Meshkin H, Kalalinia F, Peivandi MT, Hossein Khani H, Bahrami AR, et al. Comparative characteristics of mesenchymal stem cells derived from reamer-irrigator-aspirator, iliac crest bone marrow, and adipose tissue. Cell Mol Biol (Noisy-Le-Grand). 2016;62:68-74

28. Ismail HD, Phedy P, Kholinne E, Kusnadi Y, Sandhow L, Merlina M. Existence of mesenchymal stem cellsin sites of atrophic nonunion. Bone Joint Res. 2013;2:112-5. https://doi.org/10.1302/20463758.26.2000165

29. Geiger M, Li RH, Friess W. Collagen sponges for bone regeneration with rhBMP-2. Adv Drug Deliv Rev. 2003;55:1613-29. https://doi.org/10.1016/j.addr.2003.08.010

30. Zhang J, Wang JH. BMP-2 mediates $\mathrm{PGE}_{2}$-induced reduction of proliferation and osteogenic differentiation of human tendon stem cells. J Orthop Res. 2012;30:47-52. https://doi.org/10.1002/jor.21485

31. Gromolak S, Krawczenko A, Antończyk A, Buczak K, Kiełbowicz Z, Klimczak A. Biological characteristics and osteogenic differentiation of ovine bone marrow derived mesenchymal stem cells stimulated with FGF-2 and BMP-2. Int J Mol Sci. 2020;21. https://doi.org/10.3390/ijms21249726 
32. Garrison KR, Shemilt I, Donell S, Ryder JJ, Mugford M, Harvey I, et al. Bone morphogenetic protein (BMP) for fracture healing in adults. Cochrane Database Syst Rev. 2010;(6):CD006950. https://doi.org/10.1002/14651858.CD006950.pub2

33. Kämmerer PW, Pabst AM, Dau M, Staedt H, Al-Nawas B, Heller M. Immobilization of BMP-2, BMP-7 and alendronic acid on titanium surfaces: adhesion, proliferation and differentiation of bone marrowderived stem cells. J Biomed Mater Res A. 2020;108:212-20. https://doi.org/10.1002/jbm.a.36805

34. Komori T. Regulation of bone development and extracellular matrix protein genes by RUNX2. Cell Tissue Res. 2010;339:189-95. https://doi.org/10.1007/s00441-009-0832-8

35. Zhou N, Li Q, Lin X, Hu N, Liao JY, Lin LB, et al. BMP2 induces chondrogenic differentiation, osteogenic differentiation and endochondral ossification in stem cells. Cell Tissue Res. 2016;366:101-11. https://doi.org/10.1007/s00441-016-2403-0

36. Hino K, Saito A, Kido M, Kanemoto S, Asada R, Takai T, et al. Master regulator for chondrogenesis, Sox9, regulates transcriptional activation of the endoplasmic reticulum stress transducer BBF2H7/CREB3L2 in chondrocytes. J Biol Chem. 2014;289:13810-20. https://doi.org/10.1074/jbc.M113.543322

37. Tall M, Bonkoungou D, Sawadogo M, Da SC, Toe MF. Treatment of nonunion in neglected long bone shaft fractures by osteoperiosteal decortication. Orthop Traumatol Surg Res. 2014;100;Suppl:S299303. https://doi.org/10.1016/j.otsr.2014.07.005

38. Sen MK, Miclau T. Autologous iliac crest bone graft: should it still be the gold standard for treating nonunions? Injury. 2007;38;Suppl 1:S75-80. https://doi.org/10.1016/j.injury.2007.02.012

39. Caplan Al. Mesenchymal stem cells. J Orthop Res. 1991;9:641-50. https://doi.org/10.1002/jor.1100090504

40. Gómez-Barrena E, Padilla-Eguiluz NG, Rosset P. Frontiers in non-union research. EFORT Open Rev. 2020;5:574-83. https://doi.org/10.1302/2058-5241.5.190062

\section{Figures}


a

12

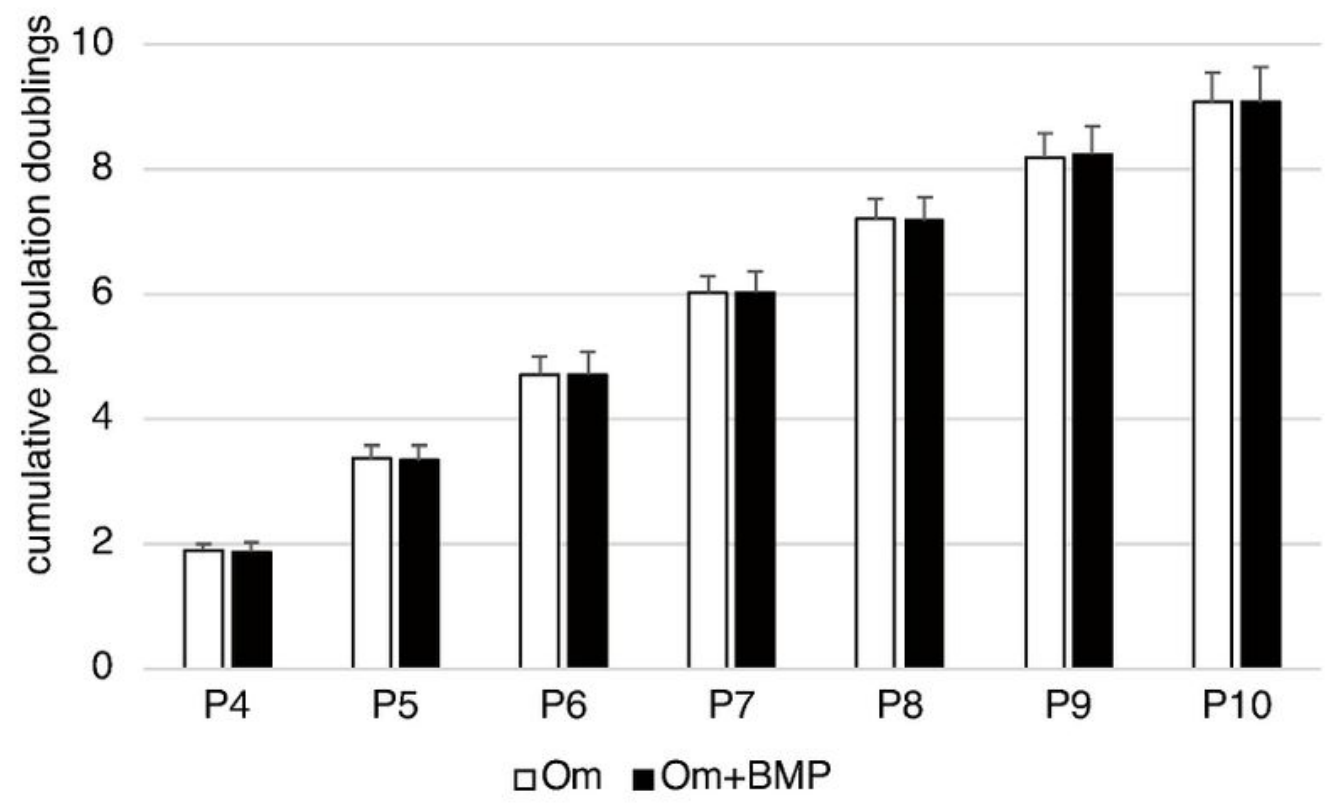

b

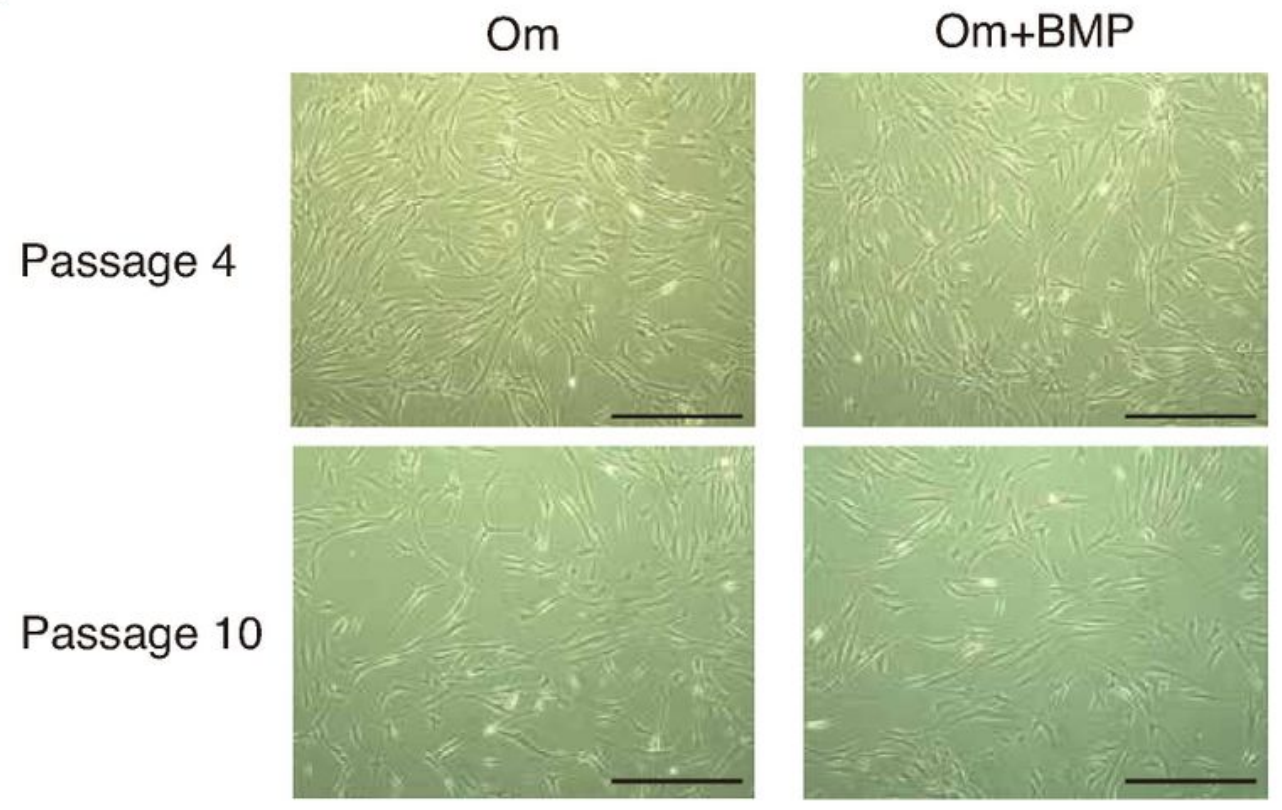

\section{Figure 1}

Evaluation of the proliferative capability of non-hypertrophic nonunion cells (NHNCs). (a) Cumulative population doublings (PD) values were determined for each subculture of NHNCs in original medium $(\mathrm{Om})$ and Om with E-BMP-2 (Om+BMP). (b) Phase-contrast images of adherent NHNCs with Om and Om+BMP displaying fibroblastoid morphology at passage 4 and 10 . Scale bar $=500 \mu \mathrm{m}$. 


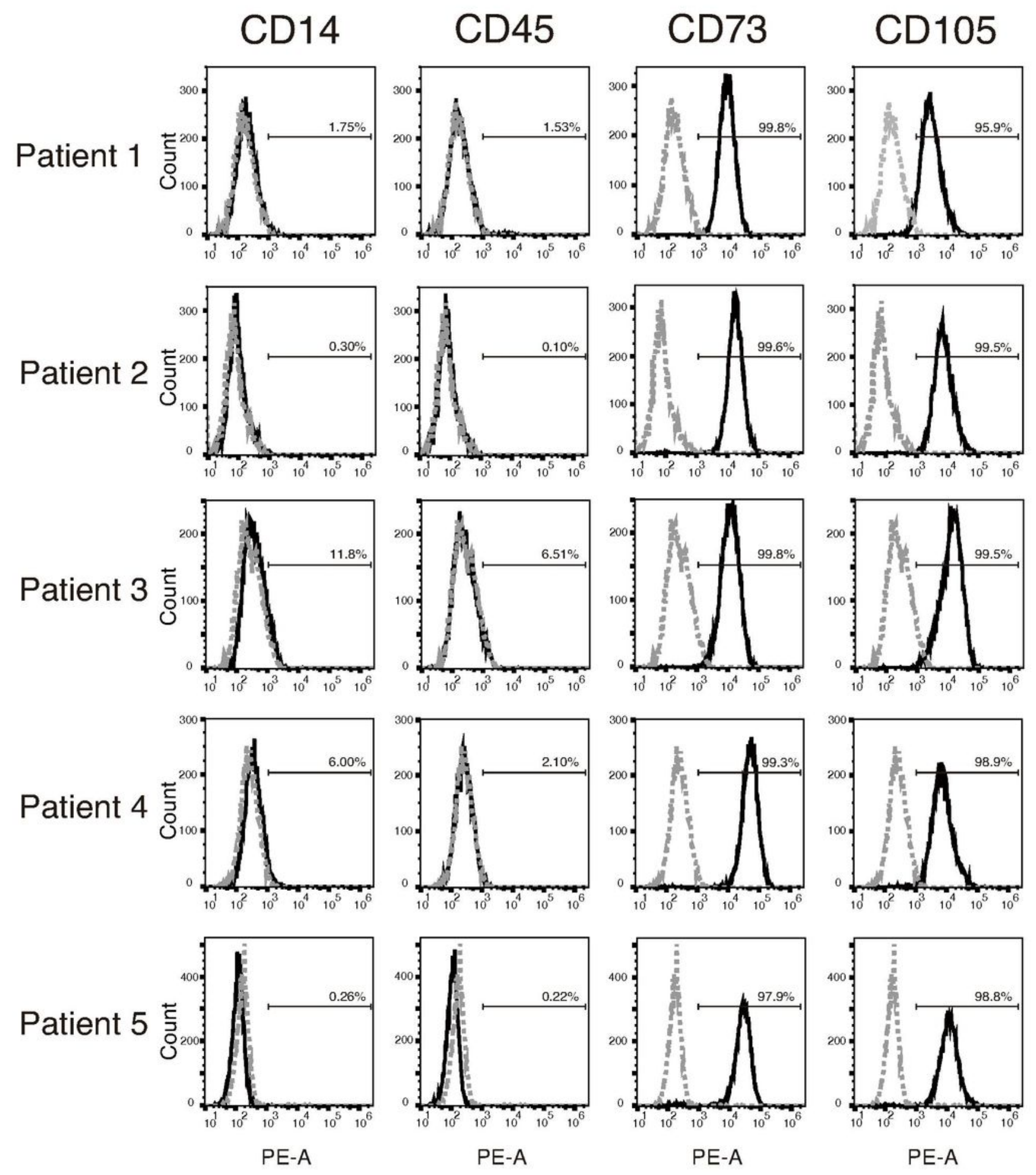

Figure 2

Flow cytometric analysis of the expression of cell surface markers of non-hypertrophic nonunion cells (NHNCs). Gray dotted lines are isotype control. Positive percentage of the cell surface is shown in each histogram. 
a
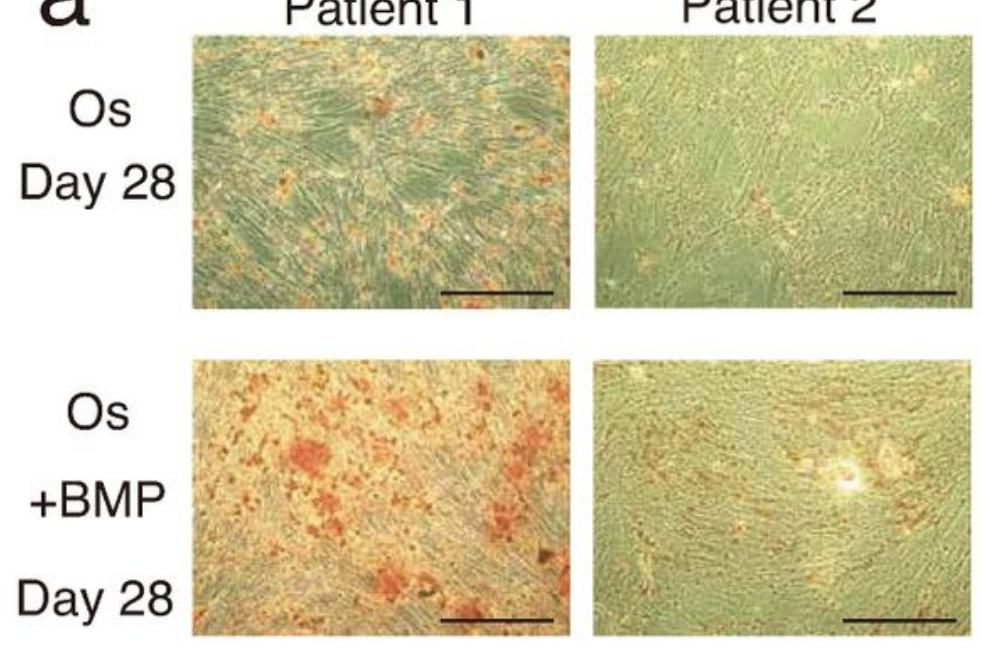

\section{Patient 4}
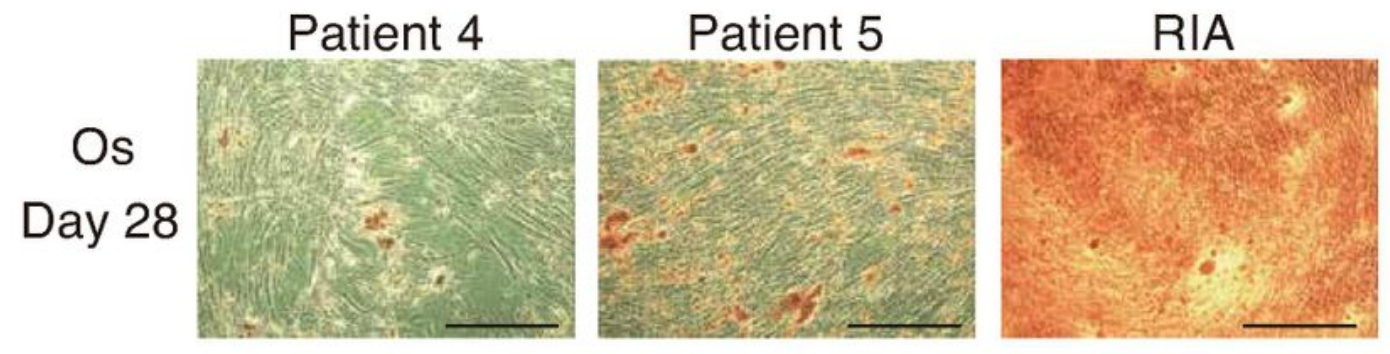
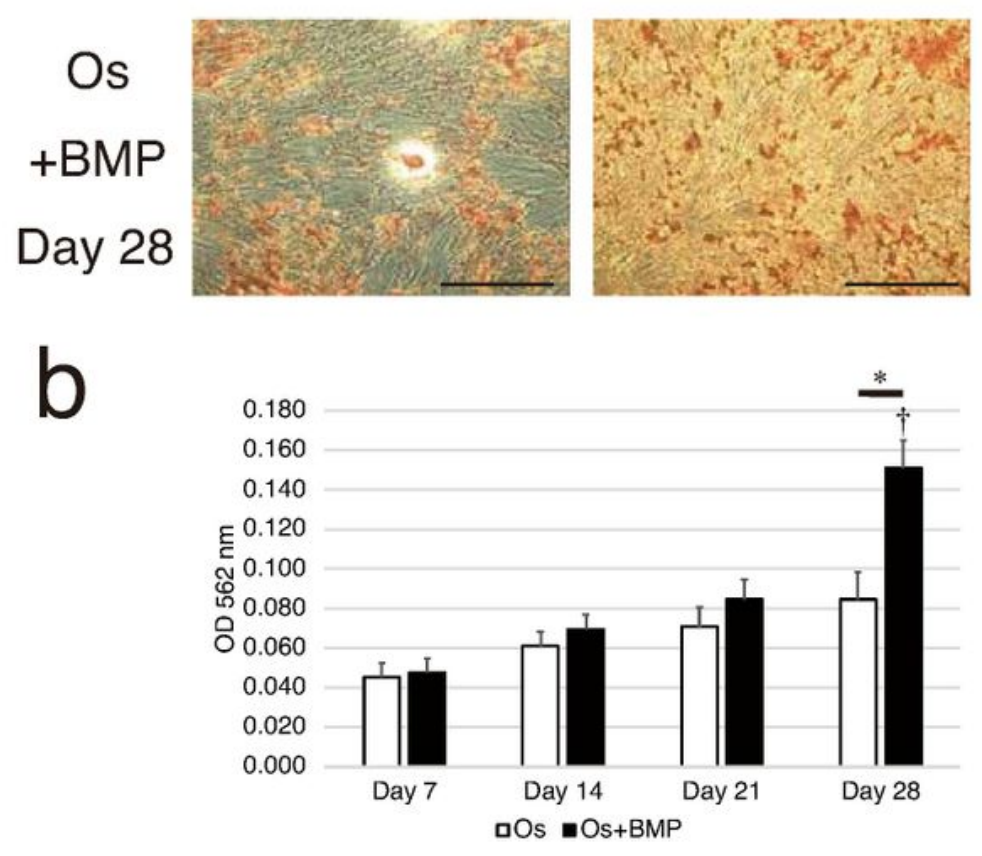

\section{Figure 3}

Analysis of the calcification capacity of non-hypertrophic nonunion cells (NHNCs). (a) Histological analysis of the osteogenic capability of NHNCs and reamer-irrigator-aspirator (RIA, positive control) stained using Alizarin Red S after 28-day incubation in osteogenic medium (Os) and Os with E-BMP-2 (Os+BMP). In Os, slightly mineralized matrix was observed as a red-stained nodule. In Os+BMP, mineralization nodule formations were more prominent. Scale bar $=500 \mu \mathrm{m}$. (b) Mineralization activity 
measured as absorbance of NHNCs in Os and Os+BMP at $562 \mathrm{~nm}$ on day 7, 14, 21, and 28. * $p<0.05$ in indicated group and ${ }^{\dagger} p<0.05$ compared with day 7 in Os+BMP group.

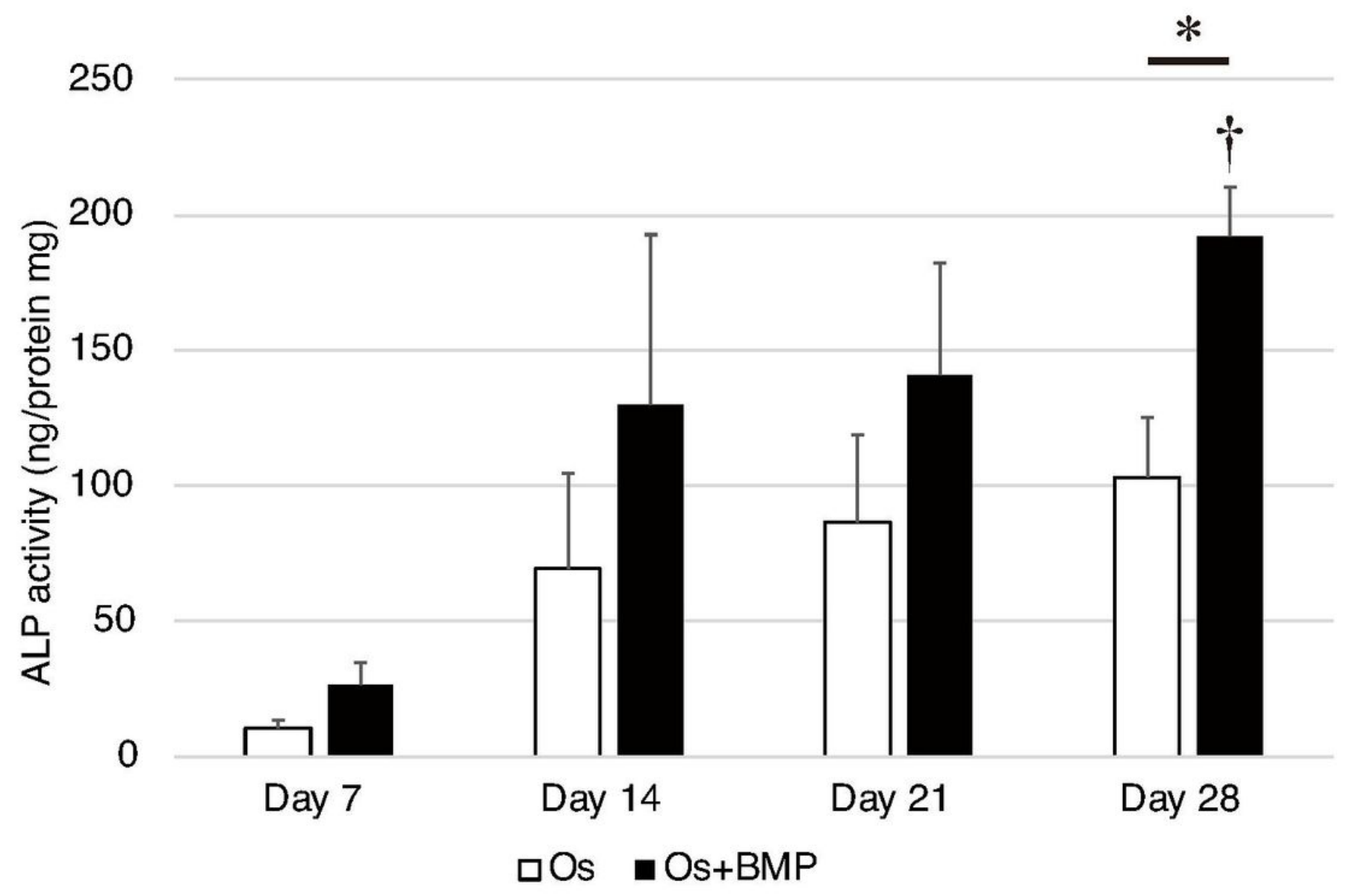

Figure 4

Analysis of the alkaline phosphatase (ALP) activity of non-hypertrophic nonunion cells (NHNCs). ALP activity of NHNCs in osteogenic medium (Os) and Os with E-BMP-2 (Os+BMP) on day 7, 14, 21, and 28. * $p<0.05$ in indicated group and ${ }^{\dagger} p<0.05$ compared with day 7 in Os+BMP group. 

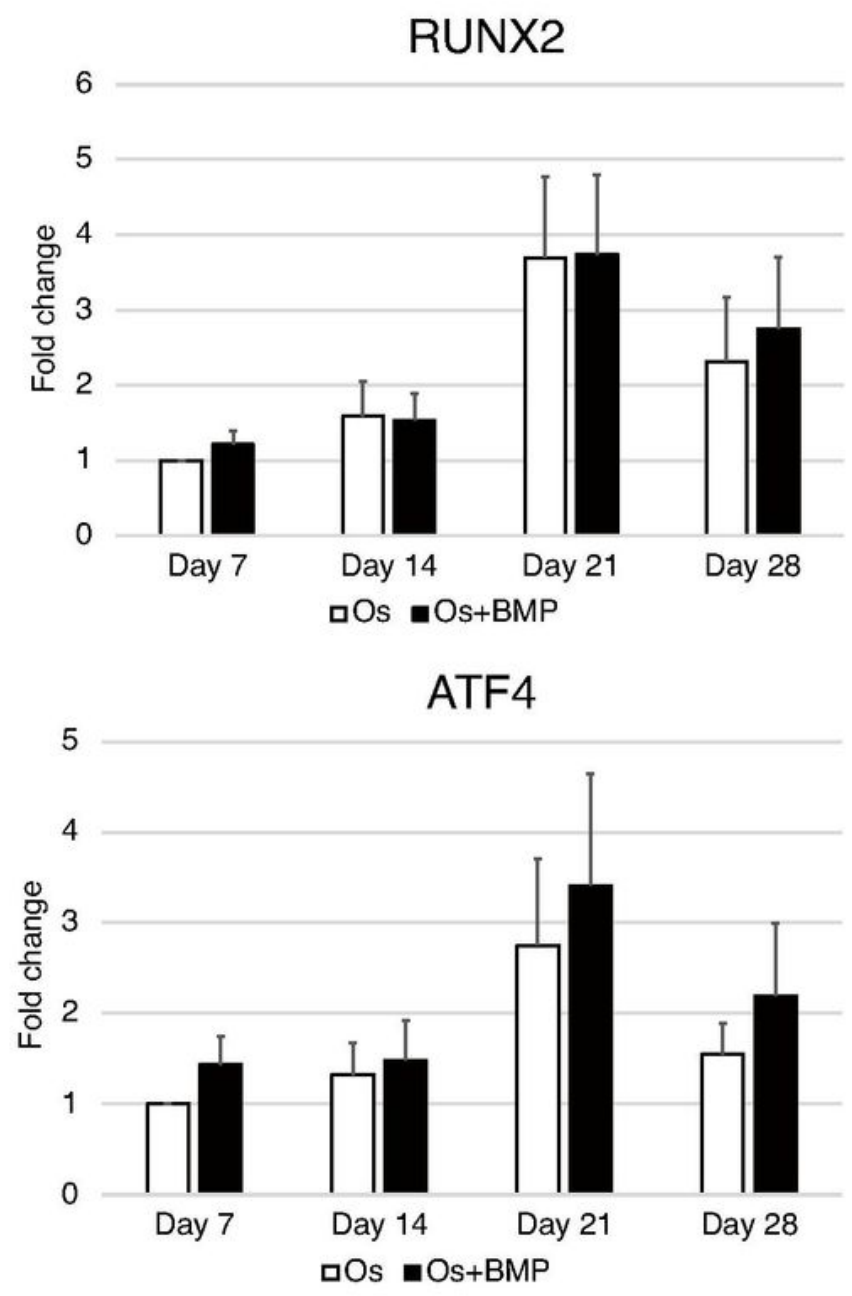

BSP

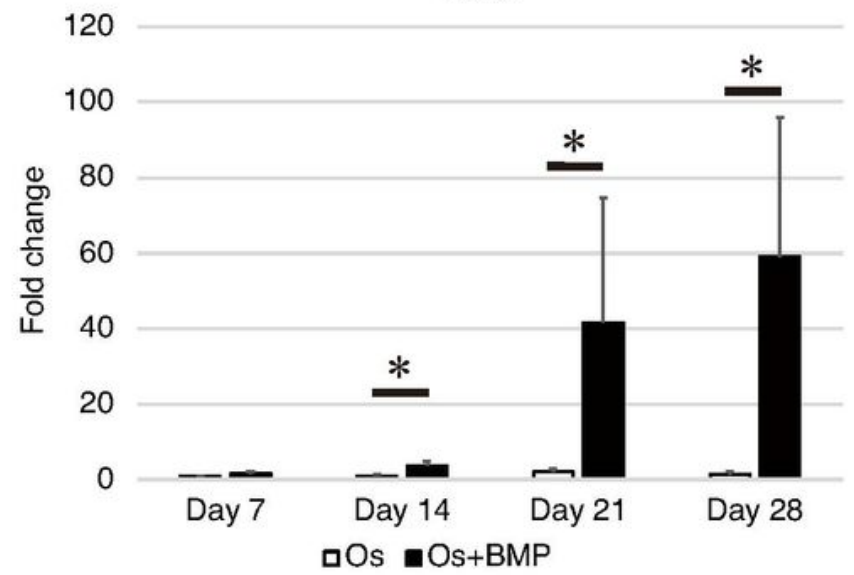

OSX
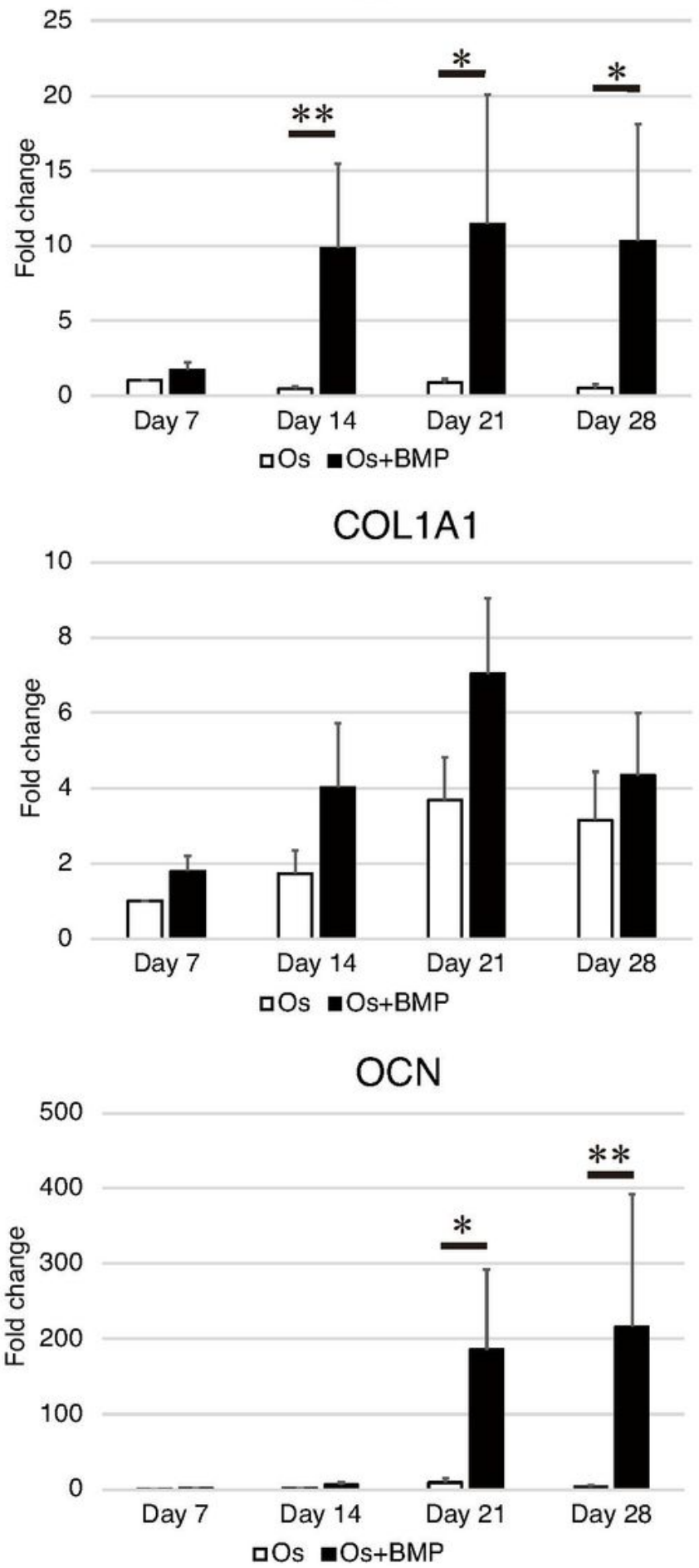

\section{Figure 5}

Analysis of the expression of osteoblast-related genes in non-hypertrophic nonunion cells (NHNCs). Realtime reverse transcription-polymerase chain reaction (RT-PCR) for runt-related transcription factor 2 ( RUNX2), osterix (OSX), activating transcription factor 4 (ATF4), collagen type I (COL 1A1), bone sialoprotein $(B S P)$, and osteocalcin $(O C M)$ in total RNA extracted from NHNCs in osteogenic medium (Os) 
and Os with E-BMP-2 (Os+BMP) on day 7, 14, 21, and 28. NHNCs in Os for 7 days were used as control. * $p<0.05$ and $* * p<0.01$ in indicated group.
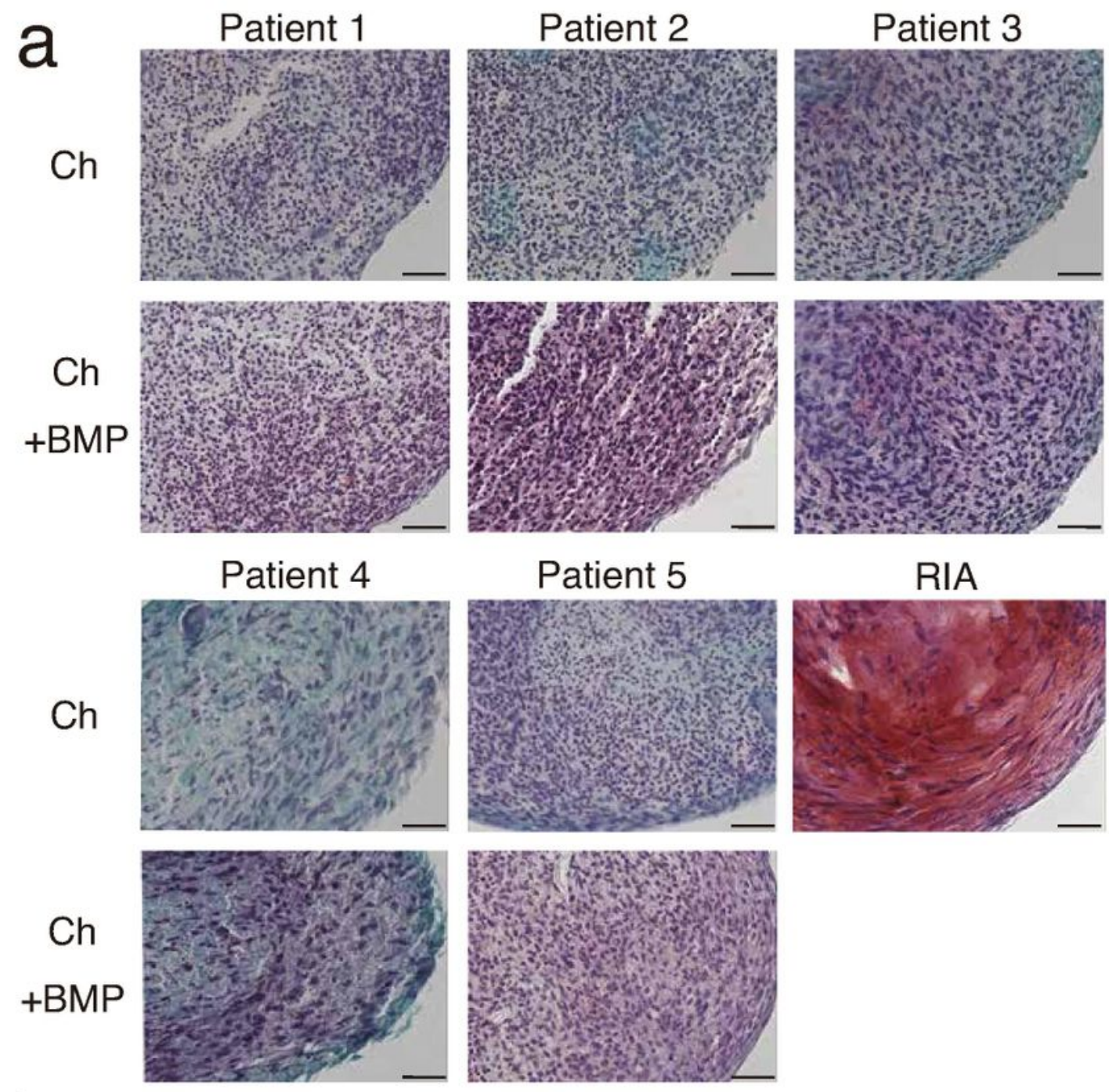

b

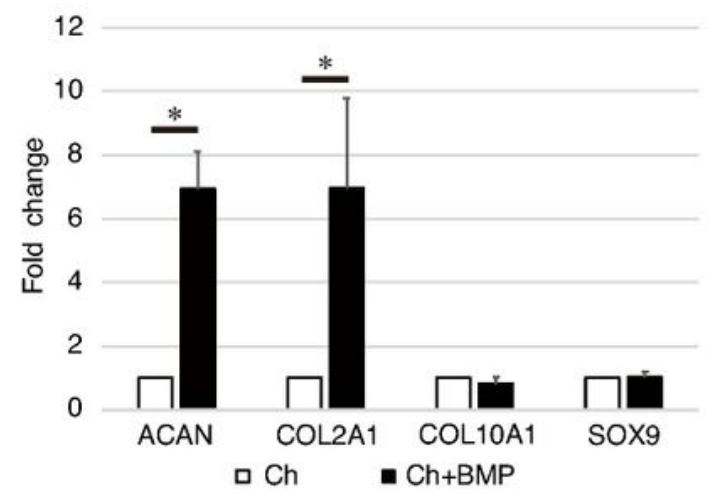

\section{Figure 6}

Analysis of the chondrogenic differentiation capacity of non-hypertrophic nonunion cells (NHNCs). (a) Histological analysis of the chondrogenic capability of NHNCs and reamer-irrigator-aspirator (RIA, 
positive control) stained using Safranin-O after 21-day incubation in chondrogenic medium (Ch) and Ch with E-BMP-2 (Ch+BMP). In Ch+BMP, high levels of glycosaminoglycan were deposited and observed as red stains in the extracellular matrix. Scale bars $=50 \mu \mathrm{m}$. (b) Real-time reverse transcription-polymerase chain reaction (RT-PCR) for aggrecan (ACAN), collagen type II (COL2A1), collagen type X (COL 10A1), and Sry-type high-mobility group box 9 (SOX9) in total RNA extracted from NHNC pellets in Ch and $\mathrm{Ch}+\mathrm{BMP}$ on day 21. NHNCs in Ch were used as control. * $p<0.01$ in indicated group. 